\title{
About the Phonetic Properties of American English
}

\author{
Vusala Babayeva ${ }^{1}$ \\ ${ }^{1}$ Department of Foreign Languages, Azerbaijan University of Languages, Baku, Azerbaijan \\ Correspondence: Vusala Babayeva, Department of Foreign Languages, Azerbaijan University of Languages, \\ Baku, Azerbaijan. E-mail: vusalababayeva@mail.ru
}

Received: June 12, 2014 Accepted: September 15, 2014 Online Published: October 3, 2014

doi:10.5539/ijel.v4n5p138 URL: http://dx.doi.org/10.5539/ijel.v4n5p138

\begin{abstract}
The article deals with the linguistic points of variation problems, the comments of various linguists dealing with the phenomenon of variation. It also deals with the formation of the realization of intra- and extra linguistic reasons of language units in speech acts in variants. The article states the separated stage of American English from the British English as an independent language as well. The differences between the investigated variants in all levels of the language have also been investigated in the article. But these differences are mostly observed in syntagmatic realization of phonological system. The materials selected from the English sources due to the pronunciation of the speakers of American and British variants have been drawn to the auditor and acoustic analyses. The language material has been experimented through the Praat program. The generalizations and points of the results in the very article are based on the experimented materials. Most linguists claim that the American variant of the English language has been separated from the British variant of the English language and is used as an independent language. The separation between the variants of American and English languages is observed in the morphological, lexical, and phonological levels of the language. But the differences between the variants are mostly observed on the phonological levels of the phonetic realization.
\end{abstract}

Keywords: variant, language, phoneme, syntagmatics, phonological system, phonetic position

\section{Introduction}

The article investigates the variants of fundamental characteristics of the language in communicative process which regulates the realization of the variants. Beside this, English has American, Canadian, Australian, New Zealand etc. variants which are called national variants. They are considered national variants of the English language according to the theoretical literature.

The determination of the variants of phonemes in phonological level, the confirmation of the relations between invariants and variants, the determination of the exact points of the diapason of variants in different language units etc. From the point of view of modern linguistics the problem of variations is both traditional and actual. The study of it through the materials based on the variants of the American English and the British English has an important role in solving the commonly stated problems in language theory and sociolinguistics.

Though the problem of variation has been investigated sufficiently in phonology, some branches need new investigation. For example, the defining of inventars of phonem variants, the investigation of relationship between invariation and variation, the determination of exact criterion of determiner of variation range of language units etc. The problem of variation has always been paid attention by the linguistics, and the theoretical research of the very problem is one of the actual problem in linguistics. The variation is investigated both in the formation of the norm of the language and in the levels of grammatical and phonological systems in modern linguistics.

The actuality of the research work is based on the comparative phonetic characteristics between the American English and the British English. It also stresses the actuality of the process of variants in linguistic aspect. The phonetic-phonological characteristics of American and English variants which were selected as a subject of investigated source are considered to be more important while comparing it with other variants of the English language which are used nowadays. The investigation gives an opportunity to predict about the perspectives of the developing variants of the linguistics and extra linguistics aspects of the typical property of American and English variants. The following problems are considered to be solved for this purpose:

-the study of the theoretical points of variants; 
-the study of inner and outer points of language units which reveal the variants in syntagmatics;

-to discover and systematize the typical phonetic properties of compared variants.

The basic morphological sources of the investigation are mainly based on the theoretical viewpoints of the linguistics who investigated the problems of variants such as L. V. Sherba (Sheba, 74), L. R. Zinder (Zinder, 79) and F. Y. Veysally (Veysalli, 73). The ossilographic method has been used while analyzing the above mentioned language materials. The phonetic experiment has been carried out by Praat program. (The program made by Holland scients. This program gives a chance to get knowledge about the acustic parametres of language voices, their modification in speech acts. Beside this, this program shows the ossilographic and spectrographic pictures of voices.)

\section{Scope of the Study}

The variation (definite and combinator variants) is observed in all levels of the language such as phonological, morphological, lexical and syntactical, etc. The units of these levels are realized in speech acts. F.Y.Versally explains the reasons of varied language units in speech: "The variants of different levels of the language depend on the rules of inner system and are regulated by the inner language rules. The situation, combination and distribution marked by inner structural variants are meant. The inner structural variants are put against the variants of sociolinguistics (the variants which are used by various idiolects and living conditions of the members of a certain language community) (Veysalli, 73).

Variation is the ability of a language which gives the same meaning in different forms. Variation is not only the result of the language evolution but also creates a basis for its development. The main cause of its formation is observed in the movement of a language through the relation of internal and external factors.

The theory of variation in modern phonology were introduced under various names such as "variation", "variance", "to be varied", "invariation", "constancy" and "norm" by L. V. Sherba, N. S. Trubeskoy, Q. P. Torsuyev, Y. S. Maslov, L. R. Zinder, F. Y. Veysally and others.

Before investigating the main points we'll discuss the linguistic meanings of the terms "variation"and "variance". Variance -is a common language property; Variation is a property of a language unit. Variation is not only the form of changing the language unit, but it is not the modification that ends to form a new language point either. V.M.Solntsev writes: "Variation demands not only changing but also stability. It is the unity of changing and stability (Solntsev, 32). Q.V.Stepanov calls variation "the results of a language evolution process. He also calls it as "material-ideal substrat" (Stepanov, 10). K.S.Gorbachevichin explains it as "the objective results of a language evolution; the attribute of a living language" (Gorbachevich, 3). He claims that variation can not be explained as the statistic point between language units (Gorbachevich, 5). F.Y.Veysally writes, "Variation is the contextually-conditioned changing of language units related to functional system and their living situations. Variation is an objective category, but it appears more apparently in the plane of expression units which are related to each other in contact and distant situations." (Veysalli, 73).

F.Veysally thinks that the language unit is subjected by a strong variation in the plane of expression because their usage of situation is not the same in syntagmatic arrow. ... On the one hand, the crossing points of segment phrases, on the other hand because of the strong effect of prosodic means cause some points in language system which did not exist in our speech earlier. These points are not given to us as ready units in a langauge system. They are very important elements though. Our speech may be monoton and unclear without them (Veysalli, 16).

The viewpoints dealing with variation may be explained in further discussions:

1. Variation is the objective results of a language development.

2. Variation may increase and discrease because of the effects of linguistic and extra linguistic factors.

3. The norm demostrates its compromising sides in some developing aspects of a language. It means that it gives an opportunity of the two variants to be used at the same time and at the same speed.

The variation or the ability of changing is one of the unseparable character of natural sign systems which refer to the human speech. Variation is the evolution of a language in hystorical plan; it is the result of mutual effects inside the system with various characters; it is also the result of the relations of languages and dialects.

The conditions of variation which are shown in both inside the system and its existance are shown in concrete sosial-hystorical situations. The general and specifical problems of variation have always been taken into consideration, but nowadays some aspects related to various problems of the development of the language, culture and society are required. These new demands make it important to look through all traditional points of language units once more. 
Firstly, the usage of different language means for signing similar and the same events in the language, any changing in the language are possible because of the evolution in the language. In this case the modification temper is possible as well. Secondly, the activity of language units in synchrony and human style exists under the name of variation ."To be varied" and "variation" are understood differently in linguistics. "To be varied" means to sign manifestations and notions, "variaton" is used as a notion related to the results of the stated process. Though they are close in meaning, they can be explained in the following ways: "to be varied" is the process which accompanies the development of the language, "variation" is the result of the expressed process in various existing variants of language units.

The analyses of theoretical sources show that the dependence of the variation of langauge units on different causes and aspects. The points are inner (system structural), outer accordance with the language system, but inner accordance with language (the development of civiliztion, making relationships among the groups of native speakers etc.), outer accordance with language system, but inner accordance with language and its activity, the aspects which are related to logical and psycological objective sides of human mind and communication. Mostly, these points are main and they determine the variation of language units.

The points which affect the development of intra- and extra linguistics should be taken into consideration. If the problem of variation is discussed, in this case the social status of native speakers, their sex, ethnic affiliation and language and speech characters of their living places should be considered too. It occurs because the speech is the marker of a person's social status and education.

The English langauge is one of the widespread languages in the world. D.Crystal writes that though English is the widespread language in the world, the Chinese is considered to be the first language due to the users of it as the Chinese is spoken by more speakers in the world than English (Crystal, 289).

While speaking English three main points should be paid attention to:

-the number of speakers using English as the first language;

-the number of speakers using English as a second language;

-the number of learners using English for special purposes.

The English language performs its social functions properly in Great Britain and the USA. It demonstrates its national variants in these countries. The national-cultural character is one of the properties of a language. The study of national-cultural characteristics of the English language proves that though they were originated from German languages, English has its own way of developing,and its unit culture.

In 1963 R.Quirk wrote that if the United States was separated from the British English and wanted to keep its independence, in this case from the linguistic point of view we'd have to speak about two langauges (Quirk, 2). It did not mean that English was fluent and perfect in England, but the American English was unclear and full of slangs (Quirk, 16).

The official language of Great Britain is the Standard English, and it captures an important place due to its polyfunctions. Today there are common features in English pronunciation and they are named as "Received Pronunciation". These are related to Oxford School and BBC company. This kind of pronunciation is considered an ideal kind of pronunciation and providesthe conditions for the English language to be used all over the world as well as its being taught as a second foreign language. R.Quirk who analized the differences in English explained the differences in grammatical structure like this:

/The sun shines but few hours each day// He states that this kind of sentence is often used nowadays. But /The sun only shines a few hours// or /The sun shines only a few hours// or /I have gotten// these kinds of sentences are considered dialectical according to the British English, though in the American English it is considered as a standard grammatical form (Quirk, 95).

The above mentioned R.Kwirk writes that English is the mother tongue of 250 million today. English is also used by many people as a second language, and the users of it reach about 450 million in the world. It means that nearly one in six speaks English in the world. That is why some specialists complain about it and think that it will tend to the hegemony of the English language and soon it will lead to the linguistic imperialism of Englsih (Quirk, 94).

English becomes a global langauge in the globalized world. It (English) has gained an official status over more than 70 counties of the world. D.Cristal writes about it on the third page of his book named as "English as a Global Language", and indicates the names of the same countries at the end of the second chapter (Cristal, 57-60). 
Though Standard English can refer to the lexics, grammar, and pronunciation, it mostly belongs to the writing. Standard English gives opportunity to communicate widely, to communicate different leves of society etc. R.Kwirk advises to distinguish Standard English from the national standard of the English language. Standard English is used not only in the political and social systems but also it is mostly used in orphography. R.Kwirk writes that /I have goten/ is pronounced dialectically in the British English, and it is not Standard English. Though it corresponds to standard grammar in the American English. But Standard English is divided into two subclasses in written and orally forms though only a few words are exceptional. England (colour, centre, levelled etc) and United States (color, center, leveled etc) use these subclasses. Canada mainly uses the British English though the American English is also preferrable. The special variants are used in Central and Western America. For example, /thru/ is used instead of /through/. Anglo-American experience is shown in some variants of orphography. For example, "7/11/98" is understood as a month of November in Europe, but it is accepted as "July 11 1998" in America. The similarity in grammar and lexics is mostly observed in writing (Quirk, 17).

\section{Comparative Variants of Phonetic Systems}

Our investigation demonstrates the results of experimental-phonetic analyses of acoustic parameters of the same language material selected from the English language (the text was sounded by both the Americans and the British citizens). The comparative variants of comparative phonetic systems in the English language show that the vocalizm has the same phoneme structure in both languages, but their usage is subjected to some definite variation in speech. The differentiated comparative signs of variants are observed in the pronunciation of vowel sounds, in their distribution, in the lengh and shortness of phonological essence.

\subsection{Phonemes}

The phoneme /i:/ is a front vowel. This phoneme has the same pronunciation in all levels in these two variants. The only tendency towards diphthongized position is observed at the end of the word, for example, /see/ (si:). It is pronounced weakly before voicless consonants such as /seat/ (si:t). Unlike the British English this phoneme is used as a final unstressed vowel in all words in American English. For example, /city/ ('sit1), /coffee/ ('kofi). Unlike the British variant the American variant of the phoneme /i:/ has longer pronunciation. The vowel /a/ which is used after the consonants in most words in American variant is pronounced. Though in the British English it is pronounced as /a:/ such as /ask/ (a:sk), /dance/ (da:ns) etc.

The phoneme $/ \varepsilon /$ is used in American English in "vowel $+\mathrm{r}$ " combinations instead of the phoneme /i:/. For example, /carry/ ('keri), /marry/ ('meri), /parrot/ ('perət) etc.

The phoneme /e/ is a front vowelin the British variant. The phoneme / $/ /$ is pronounced instead of the phoneme /e/ inAmerican English. For example, best/ (best), /well/ (wel), /very/ ('veri) etc. This phoneme has a tendency to be diphthongized in American English such as /get/ (geət).

The phoneme /a/ is rising in American variant. The phoneme / $\mathfrak{x} /$ can be used alternatively. For example, "Sam"/sæm/ və "psalm"/sa:m/ etc.

The phoneme /u/ is a back vowel. In some cases it is as /-/. The vowel/// is pronounced comparatively near the center; it is a little short and is rising less. Compare: "pool"/pu:1/va "pull"/pol/ etc.

The vowel /o/ is a middle back vowel. It is pronounced as the diphthong /o-/ especially after the consonant $/ \mathrm{r} /$ in American English. For example, "sport" /spoot/. (But in the British English it is pronounced like /spo:t/). The phoneme /o/ which is called "short-o words" in British English is observed in the following kind of words: /not/ (not), /crop/ krop), /log/ (log), /long/ (log) etc. This phoneme is less observed in American English and in some positions can be substituted for the phonemes /a/ and /o/ (ov).

\subsection{Diphthongs}

The diphthong /au/ has some vocal characteristics which are pronounced distinctly at the beginning elements in the American English. The diphthong /au/ is typical for most Americans. /au/ is pronounced as /au:/ in the American English before voiced consonants and at the end of the words such as how/ (hau), /house/ (haus), /loud/ (laud) etc.

The diphthong /a1/ is pronounced as /al/ in Standard English and American variants before voiced consonants and at the end of the words such as /wide/ (waid), /alive/ (a'la1v), /tidy/ (taid1), /knife/ (naif), /high/ (ha1) etc. But it should be noted that the first element of this diphthong /a/ wholly monophthongized before voiceless consonants in some northern parts of America and /a1/ in some southern parts of America. 
The diphthong /e1/ has differences in American English and British English if it is analyzed according to the diphthongal degree. It is wholly monophthongized in American variant, mostly in unstressed syllables, for instance, /vacation/ (ve'ke1 $\int \mathrm{n}$ ), /chaotic/ (ke'otik) etc. (But in British English (vou'ke1 $\int \mathrm{n}$ ); (ke1'otik) ) We can observe it before voiceless consonants too. For example, gate/ (get), /date/ (det). (But in British English (gett); (deit)) In other positions /e1/ which can not form syllable is clearly heard. For example, before voiced consonants such as game/ (geim), /grade/ (greld) etc. and at the end of the words such as /holiday/ ('holadeı), /birthday/ (ba: $\theta$ del) etc.

The diphthong /oə/ is pronounced as /uə/ in British English such as /sure/ ( $\left.\int u ə\right)$, /poor/ (puə) etc. It is more productive in American variant and can be pronounced without (r). For example, /four/ (foə)-"number" və /for/ (fo:)-"preposition", /hoarse/ (hoəs) - "sounding rough and unpleasant, especially because of a sore throat" və /horse/ (ho:s) "animal".

In most American regions the "retroflexsive vowel" is often heard unlike the British use a central long tense vowel(3:). For example, /bird/ (b3:d), /worm/ (wə:m), /first/ (f3:st), sister ('sistə) etc. Though figuratively, /r/ can also be pronounced in American English such as bird/ (b3:rd), /worm/ (wə:rm), /first/ (f3:rst), /sister/ ('sistə(r)) etc. Beside this, it is possible to pronounce (3(r)) in American English instead of $/ \Lambda /$ or $/ \mathrm{a}: /$.

Table 1. Retroflexive vowels

\begin{tabular}{|c|c|}
\hline British variant & American variant \\
\hline /hurry/ ('hArı) & ('h3(r)1) \\
\hline /courage/ ('k^rıdb) & ('k3(r)1dz) \\
\hline /worry/ ('w $\Lambda \mathrm{r} 1)$ & ('w3(r)1) \\
\hline
\end{tabular}

In English while pronouncing the sound $/ \mathrm{r} /$ the tongue is observed to be trembling after the vowel at the end of the word and before the consonant. The sound $/ \mathrm{r} /$ is not pronounced together with the vowels but pronounced after them except only after the vowels /a/, / / /, /i/ as in characterising ('kærəktəraızın), turn (t3:rn), hurt (h3:rt), shirt $\left(\int_{3}: \mathrm{rt}\right)$, playwright ('pleirait) etc. The sound $/ \mathrm{r} /$ becomes fricative before apical consonants $(\mathrm{t}),(\mathrm{d}),(\mathrm{s})$ in American English and with this it gets closer to its British variant.

The vowel /a/ is put against the vowel /a:/ in British English, but the vowel /a/ is not generally used in American English. In English literary pronunciation two vowel phonemes co-ordinate with one vowel phoneme in American variant. Both these two variants have the vowels of /a/ and /a:/, though mostly /a/ is used in British variant, /a:/ is often used in American variant. But /cot/ (kot) and /caught/ (ko:t) are pronounced as homophones in the western part of America, sometimes /a/ is pronounced instead of /a:/.

No strong differences are not observed in the consonant systems in the compared languages. The difference can only be observed in the distribution of consonants.

The phoneme /r/ is widely spread in the American English. The phoneme / $\mathrm{r} /$ after the vowel phonemes is pronounced (in English "rhotic pronunciation", "rhoticity") in the American English. The British English does not have such a kind of pronunciation. The phoneme $/ \mathrm{r} /$ has the character of "retroflexsive (r)" in American variant. The northern American regions keep the pronunciation of postvocal retroflexsive / $\mathrm{r} /$. For example, /farm/ (fa:rm), court (kə:rt), /far/ (fa:r), /core/ (kə:r). This allophone is realized connected with the previous word.

Table 2. Allophones

\begin{tabular}{ll}
\hline British variant & American variant \\
\hline /cart/ (ka:t) & (ka:rt) \\
/here/ (hı) & (hır) \\
/poor/ (poə) & (por) \\
\hline
\end{tabular}

The phoneme /t/ has voiced pronunciation between the paragraphs in American variant, but this blade voiceless consonant has the same pronunciation in all positions.

If the phoneme $/ \mathrm{w} /$ precedes the phoneme $/ \mathrm{h} /$, itcan betypically pronounced in the American variant such as /whether/ (whelə(r)), /whine/ ('whain), /whale/ (whe1) etc. This phoneme is not pronounced in British English. 
The phoneme /1/ is only realized with dark allophone in the American English, for instance, /dark/ (da:rk). The phoneme $/ 1 /$ is soft in the intervocalic position ( $\left.l^{\prime}\right)$, and it is hard ( () at the end of the word in British variant.

In the British English the phoneme $/ \mathrm{j} /$ is pronounced as $/ \mathrm{j} /$ before the vowel $/ \mathrm{u} /$ in the words like /tune/ (tju:n), /due/ (dju:), /dew/ (dju:), /few/ (fju:) etc., but it is not pronounced in the American variant/tune/ (tu:n), /due/ (du:), /dew/ (du:), /few/ (fu:) etc.

The phoneme $/ \mathrm{s} /$ is pronounced as $/ \mathrm{J} /$ instead of $/ \mathrm{s} /$ in American variant such as /issue/( $\left.1 \int \mathrm{u}:\right)$, /sensual/

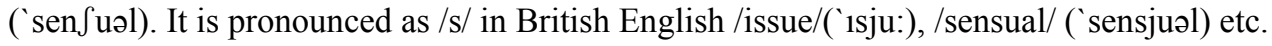

In the British English the phoneme /s/ can be used instead of the sound /z/ such asin the word /impresario/ ('ımprə'za:riəo); in the American variant it sounds different ('ımprə'sa:riou).

The dental voiced consonant $/ \mathrm{w} /$ has the same pronunciation in both variants, but it becomes a little hard between paragraphs in some southern parts of America for instance, without/ (w1`1aut).

The phoneme $/ \int /$ is used instead of $/ 3 /$ in the American variant. For example, /asia/ for British variant ('e1 $\int ə$ ), for American variant ('e13ə); /version/ for the British variant ('vz: $\left.\int \mathrm{n}\right)$, for the American variant ('v3(r)3n).

\section{Conclusion}

The concise phonetic properties of the British and the American variants of the English language show that though there are some differences in their pronunciation, they do not carry many unclear propeties. The Standard Voice System is being formed in America because of their ways of pronunciation of the American English. The main phonetic differences between English and American variants depend on the pronunciation characteristics of separate phonems.

\section{References}

Abercrombie, D. (1967). Elements of General Phonetics. Oxford University Press.

Crystal, D. (2002). English as a Global Language. Cambridge University Press.

Gorbachevich, K. S. (1978). Variance of speech and language norm. Leningrad.

Maslov, U.S. (1987). Introduction to Linguistics. Moscow.

Quirk, R., Greenbaum, S., Leech, G., \& Svartnik, J. (1997). A Grammar of Contemporary English (22nd ed.).

Sherba, L. V. (1974). Language system and speech activity. Leningrad

Solntsev, V. M. (1977). Language as a system-structural formation. Moscow

Stepanov, G.V. (1979). On the problem of language variation. Moscow

Topchuyev, G. P. (1977). Constancy and variability in the phonetic system. Moscow.

Trubetskoy, N. S. (2001). Essentials of phonology. Translation from German. Baku.

Veysalli, F. (1990). The problem of varying phonemes in modern phonology.

Veysally, F. (1990). The problems of variation of language units. Baku.

Zinder, L. R. (1979). General phonetics. Moscow.

\section{Copyrights}

Copyright for this article is retained by the author(s), with first publication rights granted to the journal.

This is an open-access article distributed under the terms and conditions of the Creative Commons Attribution license (http://creativecommons.org/licenses/by/3.0/). 